\title{
Host Modification of Chlamydiae: Presence of an Egg Antigen on the Surface of Chlamydiae Grown in the Chick Embryo
}

\author{
By I. ALLAN AND J. H. PEARCE \\ Department of Microbiology, University of Birmingham, B15 $2 T T$
}

(Received 15 September 1978)

\begin{abstract}
Egg-grown chlamydiae (EGO) have a yolk sac antigen associated with their surface which is absent from cell monolayer-grown organisms (CGO). EGO infectivity was specifically neutralized by rabbit antiserum to normal yolk sac; CGO infectivity, before or after incubation with normal yolk sac material, was not neutralized. Treatment of EGO with Clostridium welchii culture filtrate, containing phospholipase $\mathrm{C}$, abolished spontaneous infectivity for monolayers and neutralization by anti-yolk sac antiserum but did not affect centrifugeassisted infectivity. The possible significance of host antigen on the chlamydial surface is considered.
\end{abstract}

\section{INTRODUCTION}

Monolayer cultures of established cell lines have now supplanted the chick embryo as the favoured host for isolation of chlamydiae from clinical material. Centrifugation (Gordon \& Quan, 1965) is used to enhance the low level of infection which usually results from incubation of organisms with static monolayers (spontaneous infection). With this technique, organisms isolated in eggs can readily be adapted to growth in cell culture without apparent change in antigenic properties (Gordon et al., 1971).

However, studies on infection of cell monolayers by the guinea-pig inclusion conjunctivitis strain (GP-IC) of Chlamydia psittaci have shown that GP-IC grown in the chick embryo (EGO) has a lower spontaneous infectivity for cell cultures than GP-IC grown in cell monolayers (CGO; Griffiths et al., 1976). EGO and CGO behave as two homogeneous populations which differ phenotypically - most probably in surface properties affecting their attachment to monolayers - and are interconvertible by a single passage in the appropriate host (Allan \& Pearce, 1979b).

Sim \& Stephen (1975), during purification of an egg-grown strain of C. trachomatis, observed that organisms were retained by immunosorbent prepared from antibody to normal yolk sac (NYS) material. Pretreatment of the organism with phospholipase C, however, markedly influenced the pattern of its interaction with both specific and unrelated immunosorbents, suggesting that alteration of the particle surface had occurred. In the light of these observations we have now examined whether EGO differs from CGO in having an associated egg antigen that allows its neutralization by antibody to NYS material and whether this behaviour is affected by enzyme pretreatment. A preliminary account of the work has appeared (Allan et al., 1976). 


\section{METHODS}

Organism. Chlamydia psittaci, strain guinea-pig inclusion conjunctivitis (GP-IC), was grown in eggs (EGO) or irradiated McCoy cells (CGO). Harvesting, purification and enumeration of organisms were as previously described (Allan \& Pearce, 1979b).

Cell culture. Preparation of irradiated McCoy cell monolayers and titration of spontaneous and centrifugeassisted infectivities of organisms were as previously described (Allan \& Pearce, 1979b).

Antisera. Antiserum to GP-IC (anti-GP-IC) was produced following the AT2 immunization schedule of Sim (1973), using egg-grown, Renografin-purified (Allan \& Pearce, 1979 b), live GP-IC as antigen. Rabbits were given subcutaneous injections of $10^{8}, 10^{8}, 10^{9}$ and $10^{10}$ organisms in complete Freund's adjuvant on days $0,10,17$ and 25 , respectively, and intravenous injections of $10^{8}$ organisms (without adjuvant) on days 46,75 and 154. Rabbits were bled on day 164 .

A globulin concentrate of rabbit antiserum to normal yolk sac material (anti-NYS) was a gift from Dr J. Stephen, Department of Microbiology, University of Birmingham (Sim \& Stephen, 1975). Sheep antiserum to normal rabbit globulin (antiglobulin) was a gift from Dr D. R. Stanworth, Department of Immunology, University of Birmingham.

The sera and concentrated globulin preparation were stored at $-20^{\circ} \mathrm{C}$; before use, the globulin preparation was diluted 1:10 in Hanks' balanced salts solution (HBSS) supplemented with $10 \%(\mathrm{v} / \mathrm{v})$ foetal bovine serum (HFBS) to give a globulin concentration equivalent to that in serum. The sera and globulin preparation were heat-inactivated at $56{ }^{\circ} \mathrm{C}$ for $30 \mathrm{~min}$; further dilutions were made in HFBS.

Enzymic treatment of GP-IC. Suspensions $(1 \mathrm{ml})$ containing $10^{8}$ organisms were incubated with enzyme solution ( $1 \mathrm{ml}$ ) for $60 \mathrm{~min}$ at $37^{\circ} \mathrm{C}$. Enzyme solutions used were: (i) a Clostridium welchii type A freeze-dried culture filtrate containing phospholipase C activity, a gift from Dr J. Stephen (Sim \& Stephen, 1975), reconstituted with HFBS to a concentration of $1 \mathrm{mg} \mathrm{ml}^{-1}$, (ii) hyaluronidase, type I (Sigma; $1 \mathrm{mg} \mathrm{ml}^{-1}$ in HBSS); (iii) bacterial protease, type V (Pronase AS, Sigma; $1 \mathrm{mg} \mathrm{ml}^{-1}$ in HBSS); (iv) trypsin, type XII (Sigma; $2 \mathrm{mg} \mathrm{ml}^{-1}$ in phosphate-buffered saline, $\mathrm{pH} \mathrm{7 \cdot 2).} \mathrm{After} \mathrm{incubation} \mathrm{with} \mathrm{enzyme} \mathrm{solution,} \mathrm{organisms} \mathrm{were}$ washed twice by centrifugation $\left(12000 \mathrm{~g}, 30 \mathrm{~min}, 4^{\circ} \mathrm{C}\right)$ and resuspension in HFBS $(10 \mathrm{ml})$, and titrated for centrifuge-assisted and spontaneous infectivity. Organisms treated with $\mathrm{Cl}$. welchii culture filtrate were rapidly filtered through a column $(1 \mathrm{ml})$ of Sephadex G-15 (Sim \& Stephen, 1975) before washing.

Infectivity neutralization. The effect on organism infectivity of treatment with either anti-GP-IC or antiNYS (stage 1 neutralization) was examined. In some cases this was followed by treatment with antiglobulin (stage 2 neutralization).

For stage 1 neutralization, equal volumes of GP-IC suspension $\left(0.3\right.$ to $0.5 \mathrm{ml}$, containing $10^{7}$ organisms $)$ and dilutions of anti-GP-IC or anti-NYS (dilution shown in Tables) were incubated at $37^{\circ} \mathrm{C}$ for $15 \mathrm{~min}$. As controls, organism suspensions were incubated with appropriate dilutions of normal rabbit serum or HFBS alone. For stage 2 neutralization, samples of the incubated suspensions were then incubated at $37^{\circ} \mathrm{C}$ for $15 \mathrm{~min}$ with an equal volume of antiglobulin (1 in 3 dilution) or HFBS. As controls, organism suspensions incubated with normal rabbit serum or HFBS in stage 1 neutralization were then incubated with antiglobulin. All samples were diluted in HFBS and titrated for spontaneous and centrifuge-assisted infectivity.

\section{RESULTS}

\section{Antibody neutralization as a probe of chlamydial surface properties}

Although antibody can inhibit chlamydial attachment to cell monolayers in spontaneous infection, measurement poses technical problems for organisms with inherently low spontaneous infectivity (Ainsworth et al., 1979). Centrifugation, which enhances infectivity, cannot be applied as it overcomes attachment inhibition by alteration of the organism-cell interaction (Allan \& Pearce, 1979a). However, if antibody-sensitized organisms are treated with antiserum to the antibody globulin (Gerloff \& Watson, 1967; Blyth \& Taverne, 1974), neutralization of infectivity can be followed by the centrifugation technique.

We tested the procedure using rabbit antiserum to GP-IC (anti-GP-IC) and sheep antiserum to rabbit globulin (antiglobulin; Table 1). Stage 1 neutralization (anti-GP-IC alone) was $91 \%$ for spontaneous infection but only $16 \%$ for centrifuge-assisted infection. However, addition of antiglobulin (stage 2 neutralization) gave at least $95 \%$ neutralization for both infection modes. Non-specific neutralization by normal serum (stage 1), or HFBS or normal serum followed by antiglobulin (stage 2) was low (maximum $20 \%$ ) throughout. The method thus appeared suitable for analysis of surface differences between EGO and CGO. 


\title{
Table 1. Differential neutralization of centrifuge-assisted and spontaneous $G P-I C$ infectivities by antiserum to GP-IC
}

\begin{abstract}
Suspensions of egg-grown organisms (EGO) were incubated $\left(37^{\circ} \mathrm{C}, 15 \mathrm{~min}\right)$ in stage 1 neutralization with anti-GP-IC or, as controls, with Hanks' balanced salts solution supplemented with $10 \%$ (v/v) foetal bovine serum (HFBS) or normal rabbit serum. In stage 2 neutralization, samples of the incubated suspensions from stage 1 were incubated $\left(37^{\circ} \mathrm{C}, 15 \mathrm{~min}\right)$ with antiglobulin or, as a control, with HFBS. After both treatments, samples were further diluted in HFBS and titrated for centrifuge-assisted (CA) and spontaneous (S) infectivities (three replicate monolayers per sample). Neutralization is expressed as the percentage reduction in infectivity relative to that for suspensions incubated in HFBS in both stages 1 and 2.
\end{abstract}

\begin{tabular}{|c|c|c|c|}
\hline \multicolumn{2}{|c|}{ Neutralization treatments } & \multicolumn{2}{|c|}{ Infectivity neutralization ( $\%$} \\
\hline Stage 1 & Stage 2 & CA & $\mathrm{S}$ \\
\hline HFBS & HFBS & 0 & 0 \\
\hline Anti-GP-IC $(1: 96)^{*}$ & HFBS & 16 & 91 \\
\hline Normal serum $(1: 96)$ & HFBS & 7 & 13 \\
\hline HFBS & Antiglobulin $(1: 6)$ & 8 & 16 \\
\hline Anti-GP-IC (1:96) & Antiglobulin (1:6) & 99 & 95 \\
\hline Normal serum (1:96) & Antiglobulin $(1: 6)$ & 0 & 20 \\
\hline
\end{tabular}

Table 2. Effect of antiserum to normal yolk sac material (NYS) on the centrifuge-assisted and spontaneous infectivities of egg- and monolayer-grown organisms

Experimental design and presentation of results are as in Table 1, except that anti-NYS was used in place of anti-GP-IC.

\begin{tabular}{|c|c|c|c|c|c|}
\hline \multicolumn{2}{|c|}{ Neutralization treatments } & \multicolumn{2}{|c|}{ EGO } & \multicolumn{2}{|c|}{ CGO } \\
\hline Stage 1 & Stage 2 & CA & $\mathrm{S}$ & CA & $\mathrm{S}$ \\
\hline $\begin{array}{l}\text { HFBS } \\
\text { Anti-NYS }(1: 6) \\
\text { Normal serum }(1: 6)\end{array}$ & $\begin{array}{l}\text { HFBS } \\
\text { HFBS } \\
\text { HFBS }\end{array}$ & $\begin{array}{c}0 \\
4 \\
-2^{*}\end{array}$ & $\begin{array}{r}0 \\
89 \\
10\end{array}$ & $\begin{array}{r}0 \\
15 \\
-4\end{array}$ & $\begin{array}{r}0 \\
19 \\
-20\end{array}$ \\
\hline $\begin{array}{l}\text { HFBS } \\
\text { Anti-NYS }(1: 6) \\
\text { Normal serum }(1: 6)\end{array}$ & $\begin{array}{l}\text { Antiglobulin }(1: 6) \\
\text { Antiglobulin }(1: 6) \\
\text { Antiglobulin }(1: 6)\end{array}$ & $\begin{array}{r}4 \\
93 \\
9\end{array}$ & $\begin{array}{r}-8 \\
87 \\
19\end{array}$ & $\begin{array}{r}4 \\
7 \\
15\end{array}$ & $\begin{array}{r}-10 \\
-6 \\
6\end{array}$ \\
\hline
\end{tabular}

* Negative values indicate enhancement of infectivity.

\section{Presence of yolk sac antigen on the chlamydial surface}

The possibility that EGO might differ from CGO in having an egg antigen associated with their surface was tested by measuring the extent of infectivity neutralization of EGO and CGO by anti-NYS and antiglobulin (Table 2). For EGO, there was considerable neutralization of infectivity, following the same pattern as for anti-GP-IC (Table 1). Thus, only spontaneous infection was reduced in stage 1 neutralization but both centrifuge-assisted and spontaneous infection were reduced in stage 2 neutralization (Table 2). In contrast, CGO showed only low-level neutralization (Table 2) implying that neutralization of EGO by anti-NYS was specific. To confirm this point, anti-NYS was incubated with an equal volume of solution containing $500 \mu \mathrm{g}$ pelleted NYS substance $\mathrm{ml}^{-1}$ at $37^{\circ} \mathrm{C}$ for $15 \mathrm{~min}$, and then its neutralization capacity was tested. Neutralization of the spontaneous infectivity of EGO was reduced from 78 to $13 \%$ (stage 1 procedure) and after treatment with antiglobulin (stage 2 procedure) neutralization of centrifuge-assisted infectivity was reduced from 82 to $22 \%$; similar treatment of normal serum with NYS material had no effect on EGO infectivity.

Thus, EGO differed from CGO in having a surface-associated yolk sac antigen. If this 
Table 3. Effect of incubation of monolayer-grown organisms $(C G O)$ with normal yolk sac material (NYS) on neutralization of CGO infectivity with antiserum to $N Y S$

CGO were incubated at $37^{\circ} \mathrm{C}$ for $60 \mathrm{~min}$ with $1 \mathrm{mg}$ pelleted NYS substance $\mathrm{ml}^{-1}$, and then washed twice with HFBS by centrifugation $\left(12000 \mathrm{~g}, 30 \mathrm{~min}, 4^{\circ} \mathrm{C}\right)$ and resuspension, to remove excess NYS; these organisms are designated CGO/NYS. As controls, suspensions of CGO and EGO were incubated in HFBS and washed in parallel with the test sample. CGO/NYS and CGO and EGO control suspensions were then subjected to the two-stage neutralization procedure and titrated for centrifuge-assisted (CA) and spontaneous (S) infectivities (see Methods and Table 1).

\begin{tabular}{|c|c|c|c|c|}
\hline \multirow[b]{2}{*}{ Organisms } & \multicolumn{2}{|c|}{ Neutralization treatments } & \multicolumn{2}{|c|}{ Infectivity neutralization } \\
\hline & Stage 1 & Stage 2 & $\mathrm{CA}$ & $\mathrm{S}$ \\
\hline $\begin{array}{l}\text { CGO } \\
\mathrm{CGO} / \mathrm{NYS} \\
\mathrm{EGO}\end{array}$ & $\begin{array}{l}\text { HFBS } \\
\text { HFBS } \\
\text { HFBS }\end{array}$ & $\begin{array}{l}\text { HFBS } \\
\text { HFBS } \\
\text { HFBS }\end{array}$ & $\begin{array}{l}0 \\
0 \\
0\end{array}$ & $\begin{array}{l}0 \\
0 \\
0\end{array}$ \\
\hline $\begin{array}{l}\text { CGO } \\
\text { CGO/NYS } \\
\text { EGO }\end{array}$ & $\begin{array}{l}\text { Anti-NYS }(1: 6) \\
\text { Anti-NYS }(1: 6) \\
\text { Anti-NYS }(1: 6)\end{array}$ & $\begin{array}{l}\text { HFBS } \\
\text { HFBS } \\
\text { HFBS }\end{array}$ & $\begin{array}{r}-14 \\
19 \\
7\end{array}$ & $\begin{array}{r}4 \\
-9 \\
81\end{array}$ \\
\hline $\begin{array}{l}\text { CGO } \\
\mathrm{CGO} / \mathrm{NYS} \\
\mathrm{EGO}\end{array}$ & $\begin{array}{l}\text { Anti-NYS }(1: 6) \\
\text { Anti-NYS }(1: 6) \\
\text { Anti-NYS }(1: 6)\end{array}$ & $\begin{array}{l}\text { Antiglobulin }(1: 6) \\
\text { Antiglobulin }(1: 6) \\
\text { Antiglobulin }(1: 6)\end{array}$ & $\begin{array}{r}13 \\
-16 \\
95\end{array}$ & $\begin{array}{r}9 \\
12 \\
98\end{array}$ \\
\hline
\end{tabular}

Table 4. Effect of enzymes on centrifuge-assisted and spontaneous infectivities of eggand monolayer-grown organisms

Suspensions of EGO and CGO were incubated at $37^{\circ} \mathrm{C}$ for $60 \mathrm{~min}$ with culture filtrate (CF) from $\mathrm{Cl}$. welchii, hyaluronidase, trypsin or protease (see Methods) or, as controls, with HFBS. After treatment, suspensions were washed twice by centrifugation and resuspension. Samples were diluted in HFBS and titrated for centrifuge-assisted (CA) and spontaneous (S) infectivities (three replicate monolayers per sample).

$10^{-4} \times$ Infectivity titre (inclusion-forming units $\mathrm{ml}^{-1}$ )

$\begin{array}{llrcc}\text { Organisms } & \text { Enzymic treatment } & \text { CA } & \text { S } & \text { S:CA } \\ \text { EGO } & \text { HFBS } & 1050 & 1 \cdot 35 & 1: 780 \\ \text { EGO } & \text { CF } & 700 & 0^{*} & - \\ \text { EGO } & \text { Hyaluronidase } & 890 & 1 \cdot 00 & 1: 890 \\ \text { EGO } & \text { Protease } & 800 & 1 \cdot 15 & 1: 695 \\ \text { EGO } & \text { Trypsin } & 650 & 0 \cdot 85 & 1: 765 \\ \text { CGO } & \text { HFBS } & 95 & 3 \cdot 70 & 1: 26 \\ \text { CGO } & \text { CF } & 160 & 5 \cdot 50 & 1: 29 \\ \text { CGO } & \text { Hyaluronidase } & 70 & 1 \cdot 70 & 1: 41 \\ \text { CGO } & \text { Protease } & 130 & 4 \cdot 10 & 1: 31 \\ \text { CGO } & \text { Trypsin } & 230 & 8 \cdot 00 & 1: 29\end{array}$

* No inclusions detected in 100 microscope fields examined per monolayer.

had become adsorbed during isolation of organisms from the yolk sac then it would be reasonable to infer that $\mathrm{CGO}$, established as a phenotypic variant of $\mathrm{EGO}$, could be converted to EGO by incubation with yolk sac material. However, incubation at $37^{\circ} \mathrm{C}$ for $60 \mathrm{~min}$ with $1 \mathrm{mg}$ pelleted NYS substance $\mathrm{ml}^{-1}$ failed to convert CGO (spontaneous: centrifugeassisted infectivity ratio, 1:20) to EGO-like infectivity properties (spontaneous: centrifugeassisted infectivity ratio, 1:700; Allan \& Pearce, 1979b). Nor was there any evident adsorption of yolk sac antigen to CGO by the more stringent test of anti-NYS neutralization (Table 3).

\section{Susceptibility of chlamydial surface antigens to enzymic treatment}

The failure of CGO to adsorb yolk sac antigen suggested that the egg antigen associated with EGO was not an artefact of organism isolation. To gain further information on the 
Table 5. Effect of treatment of egg-grown organisms (EGO) with Cl. welchii culture filtrate on the ability of antiserum to normal yolk sac material (NYS) to neutralize EGO infectivity

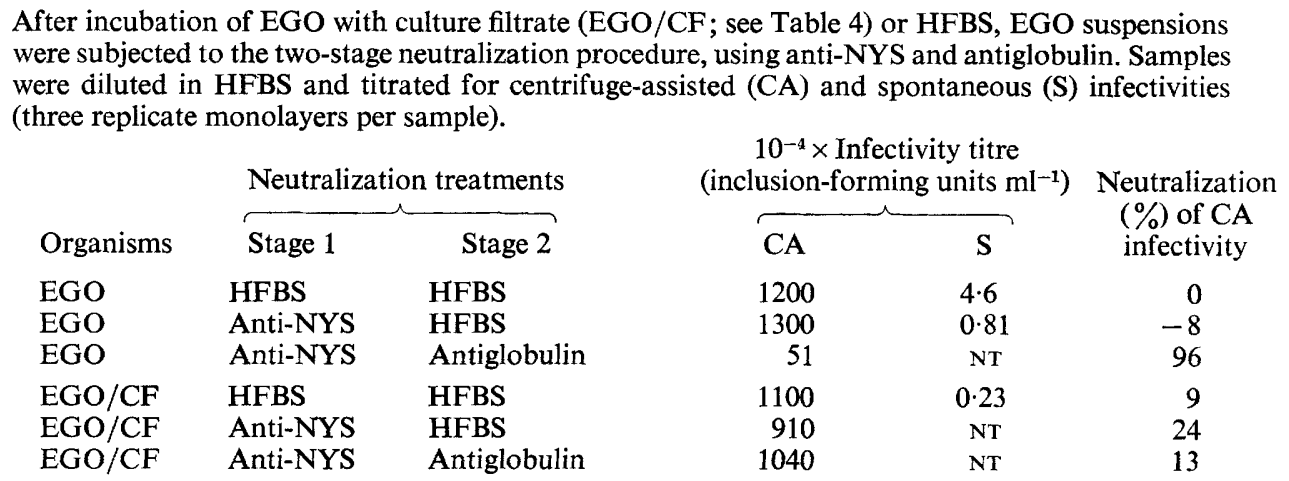

NT, Not tested: CF abolished spontaneous infectivity of EGO (Table 4).

nature of the association, the effect of various enzymes on infectivity was examined. Somewhat surprisingly, most enzymes caused little change (Table 4). Hyaluronidase, protease and trypsin did not alter EGO infectivity appreciably. However, $\mathrm{Cl}$. welchii culture filtrate (CF) containing phospholipase $\mathrm{C}$ activity completely abolished spontaneous infectivity while leaving centrifuge-assisted infectivity unimpaired - retention of the latter indicated that no inactivation had occurred. None of the treatments reduced CGO infectivity (Table 4 ); indeed, trypsin and CF caused some increase, probably by disaggregation of small clumps of organisms.

The differential action of $\mathrm{CF}$ on spontaneous infectivity provided further evidence of surface differences between EGO and CGO. Since anti-NYS had also neutralized the spontaneous infectivity of EGO it seemed possible that the egg antigen present on EGO might have been affected by the CF treatment. This was examined by comparing neutralization, by anti-NYS, of EGO infectivity before and after enzyme treatment, applying antiglobulin (stage 2 neutralization) to test for alteration in centrifuge-assisted infectivity. The latter was largely unimpaired (Table 5), indicating that CF had abolished egg antigen specificity on EGO.

\section{DISCUSSION}

EGO were previously distinguished from CGO by their lower spontaneous infectivity (Allan \& Pearce, 1979 b). We have now shown that they also differ in bearing an egg antigen (or cross-reacting antigen) and in their susceptibility to the $\mathrm{Cl}$. welchii culture filtrate. The unilateral inhibition by CF of spontaneous infection, but not centrifuge-assisted infection, is similar to the effect of attachment-inhibiting antibody (Ainsworth et al., 1979) and provides further evidence that the organism-cell interaction is altered in centrifuge-assisted infection (Allan \& Pearce, 1979a).

Unlike Blyth \& Taverne (1974) we observed little non-specific neutralization after treatment of organisms with normal serum and antiglobulin. In view of their findings it is probably always desirable to demonstrate the specificity of the antibody interaction by appropriate absorption, as was done with NYS absorption of anti-NYS.

Our results do not resolve the question of how the differences between EGO and CGO arise. EGO may differ from CGO only in respect of their egg antigen. They may carry other distinctive antigens, not so far detected, which together determine EGO affinity for cell monolayers (which probably governs spontaneous infectivity) and their behaviour towards CF. The simplest possibility is that EGO are CGO with adventitiously adsorbed egg antigen. 
However, incubation of NYS with CGO did not affect spontaneous infectivity or anti-NYS neutralization. Moreover, $\mathrm{CF}$, although apparently removing egg antigen, did not restore the spontaneous infectivity shown by CGO. It seems unlikely that CF treatment left adsorbed egg antigen residues on the EGO surface which, although no longer serologically functional, were capable of completely inhibiting spontaneous infection.

Egg antigen may be present on all chlamydiae grown in the chick embryo. In early work Moulder \& Weiss (1951) used anti-egg antiserum to purify egg-grown C. psittaci (strain feline pneumonitis) and recorded partial losses. For serological purposes, antisera raised against egg-grown chlamydiae are frequently absorbed with yolk sac material because of the yolk sac antigen invariably found in chlamydial preparations. The presence of egg antigen on the chlamydial surface would thus go unrecognized unless organisms were reacted with anti-egg antibody.

Our observations raise the question whether animal or tissue cells endow chlamydiae with a host antigen. In the preceding paper we mentioned instances in which the host appears to exert an effect on chlamydial properties (Allan \& Pearce, 1979 b). If host antigens are present on the particle surface in close juxtaposition to chlamydial antigens, then autoimmune reactions could be induced which would contribute to the immunopathological damage seen in chronic trachoma. Further, if organisms grown in one host cell infect that cell more readily than others (CGO have a higher spontaneous infectivity for cell monolayers than EGO) then modification by the host could be viewed as moderating the host range of chlamydial infections.

We thank Dr J. Stephen, and other colleagues, for helpful discussion. I. A. was in receipt of an MRC research studentship.

\section{REFERENCES}

Ainsworth, S., Allan, I. \& Pearce, J. H. (1979). Differential neutralization of spontaneous and centrifuge-assisted chlamydial infectivity. Journal of General Microbiology (in the Press).

Allan, I. \& Pearce, J. H. (1979a). Modulation by centrifugation of cell susceptibility to chlamydial infection. Journal of General Microbiology 111, 87-92.

Allan, I. \& Pearce, J. H. (1979b). Host modification of chlamydiae: differential infectivity for cell monolayers of chlamydiae grown in eggs and monolayers. Journal of General Microbiology 112, 53-59.

Allan, I., Ainsworth, S. \& Pearce, J. H. (1976). Host-induced modification of the chlamydial surface? Proceedings of the Society for General Microbiology 4, 14.

Blyth, W. A. \& TAverne, J. (1974). Neutralization of TRIC organisms by antibody: enhancement by antisera prepared against immunoglobulins. Journal of Hygiene, Cambridge 72, 129-134.

GeRLOFF, R. K. \& WATSON, R. O. (1967). The radioisotope precipitation test for psittacosis group antibody. American Journal of Ophthalmology 63, 1492-1498.

GoRDON, F. B. \& QUAN, A. L. (1965). Isolation of the trachoma agent in cell culture. Proceedings of the Society for Experimental Biology and Medicine 118, 354-359.

Gordon, F. B., Nichols, R. L. \& QuAN, A. L. (1971). Immunotyping of Chlamydia trachomatis with fluorescent antibody: retention of immunospecificity in cell culture passage, and typing with infected cell monolayers. In Trachoma and Related Disorders, pp. 358-362. Edited by R. L. Nichols. Amsterdam: Excerpta Medica.

Griffiths, M. S., Ainsworth, S. \& Pearce, J. H. (1976). Infectivity titration of guinea-pig inclusion conjunctivitis agent in irradiated McCoy cells. Journal of General Microbiology 95, 249-256.

Moulder, J. W. \& Weiss, E. (1951). Purification and properties of the agent of feline pneumonitis. Journal of Infectious Diseases 88, 56-67.

SIM, I. S. (1973). Studies on the immunospecific purification of organisms of the genus Chlamydia, p. 60. Ph.D. thesis, Birmingham University.

Sim, I. S. \& STEPHen, J. (1975). Studies on the purification of chlamydial agents grown in yolk sacs of embryonated eggs using disulphide-linked immunosorbents and enzymes. Journal of General Microbiology 89, 11-25. 